\title{
A Comparison of Table Manners between China and Norway Based on the Power Distance Theory
}

\author{
Ruoxin Wang \\ Ningbo Haiyang Vocational School, Ningbo, China \\ Email: 2227397344@qq.com
}

How to cite this paper: Wang, R. X. (2022). A Comparison of Table Manners between China and Norway Based on the Power Distance Theory. Open Journal of Social Sciences, 10, 528-536. https://doi.org/10.4236/jss.2022.102035

Received: January 22, 2022

Accepted: February 25, 2022

Published: February 28, 2022

\begin{abstract}
Table manners of work dinners are the epitome of the workplace's culture. People's different behaviors in work dinners in the presence of leaders can reflect their different attitudes towards power. This essay aims to study the different attitudes of Chinese and Norwegians towards power, and the theory framework is Hofstede's power distance theory. The author used unstructured interview to collect data. And through comparing different behaviors of Chinese and Norwegians in the seat order, the feeling/atmosphere, communicating with leaders, the willingness of toast, and toasting behaviors, it can be concluded that Chinese and Norwegians have different power values. Understanding the power distance among different countries is beneficial to establish good relations in the international workplace, and it can promote the international communication.
\end{abstract}

\section{Keywords}

Distance Power Theory, Workplace, Table Manners

\section{Introduction}

Etiquette is a code of conduct established in the objective environment. Although it has no legal significance, it needs people to abide by it just like the moral code of conduct in life, so as to enhance the relationship with others. The existence of etiquette also makes people restrict their words and deeds in the process of communication. Table manners are invisible rules that people follow when they eat. Although there are no specific regulations on table manners, due to the influence of culture, a set of established rules has naturally formed.

With the development of globalization, the number of multinational compa- 
nies is increasing. People want to have a good relationship with people in different countries in the workplace, so it is beneficial to understand other countries' culture. And work dinner is a part of workplace. People at work use the dinner to communicate with each other because of different purposes. In the work dinner where leaders are present, people's attitudes towards power can reflect their different attitudes towards leaders. People in different countries have different attitudes towards power. Studying people's attitudes towards power in different countries can assist people better establish their relationships with colleagues and bosses. This essay through comparing the different behaviors of Chinese and Norwegians in work dinners in the presence of leaders, to research their different attitudes towards the power.

\section{Research Question}

How do the different behaviors of Chinese and Norwegians in work dinners in the presence of leaders reflect their different attitudes towards the power?

\section{Literature Review}

\subsection{Power and Power Distance in the Workplace}

As McClelland (1996) stated that the definition of power has a negative connotation and is associated with abuse. People who want or need power are often labeled as dictators, dictators, duplicators and narcissists. However, without power, human behavior cannot achieve the expected results, that is, the achievement motivation. In fact, McClelland believes that leaders should embrace power, because his research shows that inhibition of power can lead to high blood pressure and other health problems. Although power has strong negative characteristics, its significance cannot be denied or ignored. Research shows that the practice of power can be both selfish and responsible.

Based on Scott (2013) the power can be defined as the ability to control valuable resources and manage rewards and punishments. The definition of power is similar to the view of resource dependence, in which power comes from the control of valuable resources. Power is different from status. Status is the position of an individual in the social hierarchy. It is also different from dominant position, which refers to the attitude of establishing or maintaining status in the social hierarchy.

Hofstede's power distance theory has been verified in a single multicultural working environment. According to Hofstede, the power distance refers to the inequality between people with more power and people with less power. Joelma D. (2015) explained that in the workplace, the inequality can be embodied by the relationship between superiors and subordinates. The power distance related to work refers to the degree of hierarchy inequality that people will accept (Stephen \& Beryl, 1994).

\subsection{Chinese and Western Table Manners}

According to Zhu (2009), Etiquette is one of the important media of interper- 
sonal communication, and dining is not only to meet the basic physiological needs, but also a very important social way. There are also many differences in the requirements of table manners between China and the West. Understanding the differences between them is beneficial to us to prevent from being rude to others. With the opening up of our country, it is of great practical significance to understand the table manners of foreign countries, especially in the West. According to the literature, at least in the Zhou Dynasty, table manners have formed a quite perfect system. As the traditional ancient Chinese table manner, there is a set of procedures, such as the host invites each other by folding the invitation card. When the guests arrive, they greet each other, introduce them to the sitting room, and the left side is the upper seat.

Based on Xiong (2015), table manners, mean that eating activities should have a certain degree of etiquette. Whether people obey these etiquette rules or not determines their position and impression in other people's eyes, from which others can also see somebody's personal cultivation and cultural background. In social communication, banquets are the most common communication activities. Mastering the different table manners between Chinese and western not only enables people to get together to enjoy the delicious food and wine, but also can relax communicate atmosphere, enhance friendship and achieve cooperation.

\section{Methodology}

\subsection{Framework}

Power distance was firstly put forward by the famous Dutch social psychologist Mauk Mulder. He defined the word power as "the potential to determine or direct (to a certain extent) the behavior of another person or other persons more so than the other way round". And he defined the power distance as the extent of unequal power between the Individual (I) with less power and Other (O) with more power, and I and O belong to the same society (Mauk, 1977).

Based on this, Hofstede defined the power distance as the degree to which less powerful members of institutions and organizations in a country expect and accept unequal distribution of power. (Hofstede, 2010) And through the questionnaire survey of IBM employers, he came up with Power Distance Index to measure the extent of inequality in a society.

According to Hofstede (2010), Power distance refers to dependence relationships between subordinates and superiors in a country. In small power distance countries, subordinates are less dependent on their superiors, and they can negotiate with superiors. While in large power distance countries, subordinates are very dependent on superiors. The reaction of subordinates is to favor this dependence or reject it.

\subsection{Research Method}

The research method is unstructured interview. Five Chinese and five Norwegians are invited to this interview. Chinese are interviewed face to face. But be- 
cause of the geography, Norwegians are interviewed by Wechat call. The interview data will be recorded, so that it can be transcribed.

\subsection{Study Population}

10 participants are interviewed, 5 are Chinese, and 5 are Norwegians. They are in the similar ages, that is between 25 and 30 years old. They engaged in different occupations, and at the bottom of the workplace. They all have the experience of eating with leaders, so they can expound their opinions about their dinning behaviors and how to handle the relationship with leaders at the dinner table. And in order to analyze the data, Table 1 is the code of study population.

\subsection{Interview Question Design}

The interview questions (appendix A) are designed according to Hofstede's power theory in the workplace. Questions 1, 2 and 3 are designed to create a relaxed interview atmosphere, so that the interviewees can feel comfortable, which means they can feel that it is just a conversation with friends. And they gradually can get familiar with the topic of the interview. Question 4 is designed to elicit the hierarchical system between subordinates and superiors. As Hofstede (2010) states that in the large power distance countries, the subordinates are unequal with the superiors, and the hierarchical system is based on this inequality. While in the small power distance countries, the subordinates are equal with the superiors, and the hierarchical system is roles' inequality, and the roles can be changed. Question 5, 6, 7 and 8 are designed to elicit the relationship between subordinates and superiors. In the large power distance countries, power is in the hands of a few. And the salary system between the subordinates and superiors is very different. While in the large power distance countries, superiors should be close to subordinates. The ideal boss is wise, so he/she is respected. Question 9,10 and 11 are designed to elicit the subordinates' attitude towards

Table 1. Details of study population.

\begin{tabular}{ccc}
\hline Group & Interviewee Nationality & Interview reference code \\
\hline \multirow{3}{*}{ Cps (Chinese participants) } & Chinese & CP1 \\
& Chinese & CP2 \\
& Chinese & CP3 \\
& Chinese & CP4 \\
& Chinese & CP5 \\
\hline \multirow{3}{*}{ NPs (Norwegians participants) } & Norwegians & NP1 \\
& Norwegians & NP2 \\
& Norwegians & NP3 \\
& Norwegians & NP4 \\
& Norwegians & NP5
\end{tabular}


their superiors. Hofstede (2010) explained that in the large power distance countries, the relationship between subordinates and superiors is filled with emotion. That is, the subordinates may extremely adore or hate their superiors.

\section{Data Analysis}

The description and analysis of interview data is anonymous. And in the process of analyzing interview data, it is impossible to present all the interview data, so the data need to be coded. As Zoltán Dornyei (2007) stated that in practice, encoding includes highlighting excerpts of transcription data and labeling them in a way that is easy to identify, retrieve, or group. I will use grounded theory to code the data. The grounded theory was first come up with by Anselm Strauss and Barney Glaser from Columbia University in 1976. And my data coding is divided into three types. They are open coding, axial coding and selective coding. The open coding is the first layer of the data analysis, and the text data is broken into blocks, and given some category labels. These labels are abstract rather than descriptive. I will use open coding to label the different kinds of behaviors of Chinese and Norwegians. The axial coding is used to establish the connections between categories. I will use axial coding to label the concrete different behaviors. Then, the selective coding is the final stage of grounded theory. It is the core category. Table 2 is the selective coding to label the purpose of different behaviors.

Table 2. The coding process.

\begin{tabular}{|c|c|c|}
\hline \multicolumn{3}{|c|}{ Chinese } \\
\hline Open coding & Axial coding & Selective coding \\
\hline Seat order & ve the concrete seat order & show respect to the leaders \\
\hline The feeling/atmosphere & reserved & $\begin{array}{l}\text { need to pay attention to the } \\
\text { own words and deeds }\end{array}$ \\
\hline $\begin{array}{l}\text { Communicate with } \\
\text { leaders }\end{array}$ & ry to avoid conversation & worry about saying the wrong thing \\
\hline The willingness of toast & willing to toast & \multirow[t]{2}{*}{ show the respect } \\
\hline Toasting behaviors & very formally & \\
\hline \multicolumn{3}{|c|}{ Norwegians } \\
\hline Open coding & Axial coding & Selective coding \\
\hline Seat order & no fixed seat order & no rule about it \\
\hline The feeling/atmosphere & encouraged and relaxed & it's the boss's job \\
\hline Communicate with leaders & $\begin{array}{l}\text { willing to communicate } \\
\text { to the leader }\end{array}$ & $\begin{array}{l}\text { have a good relationship } \\
\text { with the boss }\end{array}$ \\
\hline The willingness of toast & can have a toast or not & no rule about it \\
\hline Toasting behaviors & informally & show gratitude or encouragement \\
\hline
\end{tabular}




\subsection{Description of Data}

\subsubsection{Seat Order}

Participants described the seating before the dinner. CPs stated that in China, there is a concrete seating arrangement. The leader takes the seat first and sits towards the gate. This is the upper seat. The rest people sit on both sides of the boss according to their positions. And CP2 further explained that she is a clerk at the bottom of the apartment, and usually sits at the serving position.

While NPs said that in Norway, like many western countries, very formal situations such as weddings and conferences will have fixed seating arrangements to avoid embarrassment and confusion. If it is a general department dinner, there will be no seating arrangement. Generally, leaders are invited to choose their seats first, then the employees take their own seats.

\subsubsection{The Feeling/Atmosphere}

Participants expounded the atmosphere and feeling during the work dinner. CPs said that the atmosphere was a little restrained, because they should pay attention to their words and deeds and not leave a bad impression on the boss. After all, appreciation and salary increase are all dependent on the leadership. And CP2 further explained that although the boss tries to make the atmosphere as relaxed as possible, she also pays attention to the statements and actions and doesn't want to leave a bad impression on the boss.

In contrast, NPs stated that the atmosphere is relaxed encouraged. If they are sitting with a familiar colleague, they will feel very comfortable. And it's the boss's job to relax the dining atmosphere. NP3 further explained that the general atmosphere is good, but if you want to talk about the work with the boss, you need to pay attention to what you say.

\subsubsection{Communicate with Leaders}

Participants expounded their willingness to communicate with leaders. CPs stated that they try to avoid speaking to leaders. Unless the topic is to active the atmosphere or related to themselves. If the topic is about economy or politics, they will not come up with any opinions. And CP3 further explained that sometimes he wants to have a good relationship with the leader, he will echo the leader's words.

While NPs stated that they are willing to communicate with the bosses, and many topics during the work dinner are not related to the job. But if the content of the topic is related to the job, they are also willing to discuss with the boss, and the boss doesn't like the employees not to be frank or just echo what he/she said.

\subsubsection{The Willingness of Toast}

Participants expounded their willingness of toast to the leader. CPs stated that they are willingness to toast to the leader. Because this is the Chinese traditional etiquette, and they also want to show their respect to the leader in this way or hope that the leader can appreciate them. 
But NPs said that there is no rule that they have to toast to the leader. They toast only under the boss's or other people's proposal, and show their gratitude and encouragement to others through toasting. They toast to their bosses usually want to show their gratitude.

\subsubsection{Toasting Behaviors}

Participants expounded the toasting etiquette in their country. CPs stated that first, they leave the seat, and hold the cup with both hands. Then, take some reasons, such as some words to show the respect to the leader. When clinking the cup, their cups should be lower than that of the leaders. Then they try to finish the wine in the cup, but the leader can choose to finish or not.

While NPs said that there seems to be no specific toasting etiquette. They said that if they are far from someone they want to toast to, they just raise their cups. And if they are near to someone they want to toast to, they just leave the seat, and clink the cups with him/her, then drink wine.

\section{Analysis and Discussion}

\subsection{Seat Order}

In this part, Chinese show different attitudes towards the power from the Norwegians. In China, to the leaders or the elders, there is a special name and position of the seat. It is the upper seat that towards the door. Chinese ask the leaders to sit in this position to show their respect. While in Norway, there is no such rule, and they just ask the boss to take a seat first, but the seat is not fixed. As Hofstede (2010) stated that in large power distance countries, children are taught to obey their parents, and they should respect the elders. As they enter the workplace, the relationship between parents and children will also be brought into it, and transformed into the relationship between subordinates and superiors. China is a large power distance country, Chinese understand the leaders as the symbol of the power, so they are willing to respect the leaders.

\subsection{The Feeling/Atmosphere and Communicate with Leaders}

In this part, Chinese seem to be more afraid of the boss than the Norwegians, and try to avoid talking to leaders. Hofstede (2010) explained that in the power distance country, the subordinates are unequal with the superiors, and the power is in the hands of a few. In addition, the subordinates want to be what to do. Based on this, Chinese try to avoid talking to leaders because the leaders' topic is not about him/her, and the leader doesn't ask he/she to talk to. Besides, the performance of the subordinates is judged by the leader, and the subordinates don't want to make a bad impression on the boss by saying something wrong. Because the bad performance at the work dinner is likely to affect the future career development. While in the small power distance country, the subordinates are equal with the superiors, and the roles can be changed. The superiors should be closer to the subordinates, and the ideal superior is respected because of the intellect (Hofstede, 2010). Norway is a small power distance country, and the rela- 
tionship between the superiors and the subordinates is partnership. The boss wants to listen to the subordinates' suggestions on the work, and plan the development of the company together. In addition, the boss is closer to the subordinates, and respects their own ideas. So, the subordinates are also willing to talk to the boss about non work topics.

\subsection{Toast Behaviors}

In this part, Chinese respect the leader more than Norwegians. Toasting to the elders is the traditional etiquette in China because of the power culture. In large power distance country, like China, the salary, promotion and employment of the subordinates are determined by the leader alone. In the work dinner, subordinates use toasting to flatter leaders, hoping that leaders can appreciate themselves and give them the opportunity of promotion and salary increase. As Hofstede (2010) stated that in small power distance country, salary ranges between the superiors and subordinates are relatively small, and the organizations are quite decentralized. So, in Norway, subordinates don't have to flatter the boss, because they are in the same team. The working mode is not management and being managed, but cooperation.

\section{Conclusion}

The different behaviors of Chinese and Norwegians in work dinners in the presence of leaders reflect their different attitudes towards the power. Understanding the power values of different countries is conducive to building a good relationship with leaders in the workplace of multinational companies, and it also meets the needs of the development of the globalization. Moreover, through this study, I deepen the understanding of the power culture of my own country. Although sometimes I also dislike some behaviors in the domestic workplace, I am in this cultural environment and can only adapt to it. Besides, there are also some weaknesses in this study, such as the sample may be too few to comprehensively reflect a country's power culture.

\section{Conflicts of Interest}

The author declares no conflicts of interest regarding the publication of this paper.

\section{References}

Hofstede, G. (2010). Cultures and Organizations: Software for the Mind. McGraw-Hill.

Joelma D. (2015). The Influence of Power Distance on the Communications between Superiors and Subordinates in the Brazilian Workplace. School of Social Sciences, History and Philosophy, 25.

McClelland, D. C. (1996). Power Is the Great Motivator. Harvard Business Review, 73, 126-139.

Mulder, M. (1977). The Daily Power Game. Springer US.

https://doi.org/10.1007/978-1-4684-6951-6 
Scott, S. (2013). Power, Moral Clarity, and Punishment in the Workplace. The Academy of Management Journal, 56, 1002-1023. https://doi.org/10.5465/amj.2010.0960

Stephen, B., \& Beryl, H. (1994). Power Distance, Individualism/Collectivism, and Job-Related Attitudes in a Culturally Diverse Work Group. Journal of Cross-Cultural Psychology, 233-257. https://doi.org/10.1177/0022022194252005

Xiong, Y. L. (2015). The Discussion of the Differences between Chinese and Western Table Manners. Cultural Highlands, 283.

Zhu, G. (2009). An Analysis of the Differences between Chinese and Western Table Manners. China's Foreign Trade, 10.

Zoltán, D. (2007). Research Methods in Applied Linguistics. Oxford University Press.

\section{Appendix A}

What's your job?

Do you like your job?

How often do you have a work dinner?

When having dinner with colleagues (leaders also participate), are there seat orders?

What's the atmosphere of work dinner?

Who is the initiator of discourse?

Are you willing to talk directly with the leader, or do you echo what the leader say?

Are you willing to toast to the leader during the dinner? Why or why not?

Can you elaborate on the toast manners in your country? 